Cell Research (1999), 9, 61-69

\title{
Tropomyosin is localized in the nuclear matrix and chromosome scaffold of physarum polycephalum
}

\author{
Zeng Xian Lu ${ }^{1}$, Ming Da JiaO ${ }^{1}$, Miao Xing ${ }^{1 *}$, Xiao Guang \\ $\mathrm{WANG}^{2}$, SHUI HAO ${ }^{1}$ \\ 1 Institute of Genetics and Cytology, Northeast Normal \\ University, Changchun 130024, China \\ 2 Department of Biology, Changchun Normal College, \\ Changchun 130032, China
}

\begin{abstract}
The nuclei and chromosomes were isolated from plasmodia of Physarum polycephalum. The nuclear matrix and chromosome scaffold were obtained after the DNA and most of the proteins were extracted with DNase I and $2 \mathrm{M} \mathrm{NaCl}$. SDSPAGE analyses revealed that the nuclear matrix and chromosome scaffold contained a $37 \mathrm{kD}$ polypeptide which is equivalent to tropomyosin in molecular weight. Immunofluorescence observations upon slide preparations labeled with anti-tropomyosin antibody showed that the nuclear matrix and chromosome scaffold emanated bright fluorescence, suggesting the presence of the antigen in them. Immunodotting results confirmed the presence of tropomyosin in the nuclear matrix and chromosome scaffold. Immunoelectron microscopic observations further demonstrated that tropomyosin was dispersively distributed in the interphase nuclei and metaphase chromosomes.
\end{abstract}

Key words: Chromosome scaffold, nuclear matrix, Physarum polycephalum, tropomyosin.

\section{INTRODUCTION}

The nuclear matrix and chromosome scaffold are the residual fibrillar network 
Tromyosin localized in Physarum polycephalum

structures of the nucleus and chromosome which are depleted of DNA, histone and most of nonhistone proteins[1-6]. These two structures are dynamic during the cell cycle and play important roles in various activities essential for the cell life[7-9]. The main component of nuclear matrix and chromosome scaffold is nonhistone proteins[1-4],[10]. Although many biochemical and immunocytochemical analyses have been conducted concerning protein composition of the nuclear matrix and chromosome scaffold, only a few proteins (such as topoisomerase II) have been identified[11-16]. Some previous biochemical analyses indicated that a polypeptide of about $37 \mathrm{kD}$, which is equivalent to tropomyosin in molecular weight, existed in the nuclear matrix and chromosome scaffold [15], [17-20] and this polypeptide might represent tropomyosin[19]. In order to gain a clear idea whether tropomyosin exists in the nuclear matrix and chromosome scaffold, we analysed the protein composition of the nuclear matrix and chromosome scaffold of $P$. polycephalum with SDS-PAGE and localized tropomyosin in the nuclear matrix and chromosome scaffold with immunodotting, immunofluorescence and immunoelectron microscopy.

\section{MATERIALS AND METHODS}

\section{Strain resource and culture methods}

Strain TU291 was a gift from Dr. Philipe Albert, Cytobiology Laboratory of Reims University, France, and the culture method was referred to Daniel and Baldwin[21].

\section{Preparations of nuclear matrix and chromosome scaffold}

Nuclei were isolated from the plasmodia of suspension culture referred to the method of Mohberg and Rusch[22]. The procedure of isolating chromosomes was as follows: the synchronized plasmodia were monitored with light microscope at regular intervals, and the plasmodia at metaphase was put into the isolation solution precooled in ice-water; metaphase nuclei were isolated according to the method of Mohberg and Rusch[22], the isolated metaphase nuclei were resuspended in the isolation solution, disposed twice with ultrasonic waves (each for $30 \mathrm{sec}$ ), centrifuged at $3000 \mathrm{~g}$ for $20 \mathrm{~min}$, and chromosomes were obtained by purifying the sediments. The isolated interphase nuclei and metaphase chromosomes were suspended in Tris buffer $(2 \mathrm{~m} M$ Tris- $\mathrm{HCl}, 50 \mathrm{mM} \mathrm{NaCl}, 10 \mathrm{mM} \mathrm{MgCl}, 1 \mathrm{mM} \mathrm{PMSF}, \mathrm{pH} 7.4$ ), digested with $200 \mathrm{mg} / \mathrm{ml} \mathrm{DNase} \mathrm{I} \mathrm{at}$ $37{ }^{\circ} \mathrm{C}$ for $30 \mathrm{~min}$ and disposed with $2 \mathrm{M} \mathrm{NaCl}$ at room temperature for $20 \mathrm{~min}$. The final specimens were obtained after washing and centrifuging.

\section{SDS-PAGE analysis}

Nuclear matrix and chromosome scaffold were dissolved in Laemmli buffer[23], heated at 100 ${ }^{\circ} \mathrm{C}$ for $4 \mathrm{~min}$ and centrifuged to remove residuals. Slab gel electrophoresis was carried out in the presence of SDS according to Laemmli[23] using 12\% polycrylamide. The gels were stained with Coomassie Blue (R-250) and decolored in alcohol-acetate.

\section{Indirect immunofluorescence labeling}

Isolated interphase and metaphase nuclei were fixed in $45 \%$ acetic acid for $10 \mathrm{~min}$ and squashed on slides. Cover slips were removed with the liquid nitrogen method and then the specimens were postfixed in $4 \%$ paraformaldehyde for $20 \mathrm{~min}$, washed in $10 \mathrm{mM}$ PBS for $20 \mathrm{~min}$, disposed with 
Zeng XL et al.

$2 \mathrm{M} \mathrm{NaCl}$ at room temperature for $20 \mathrm{~min}$, washed in $10 \mathrm{mM}$ PBS for $10 \mathrm{~min}$, digested with 200 $\mu \mathrm{g} / \mathrm{ml}$ DNase I at $37{ }^{\circ} \mathrm{C}$ for $30 \mathrm{~min}$. After washing in $10 \mathrm{mM}$ PBS, the specimens were blocked with $1 \%$ bovine serum albumin (BSA) for $30 \mathrm{~min}$, incubated with rabbit anti-tropomyosin antibody (T 3651, purchased from Sigma) at a 1:30 dilution in PBS containing $0.1 \%$ BSA at $37{ }^{\circ} \mathrm{C}$ for $1 \mathrm{~h}$ and then at $4^{\circ} \mathrm{C}$ overnight, washed with $10 \mathrm{mM}$ PBS, incubated with FITC conjugated sheep antirabbit IgG antibody at a 1:40 dilution in PBS containing $0.1 \%$ BSA at $37^{\circ} \mathrm{C}$ for $1 \mathrm{~h}$. Controls were exposed only to FITC conjugated sheep anti-rabbit IgG antibody. Finally, the specimens were covered with $90 \%$ glycerol, observed and photographed with Olympus BAH-2 fluorescence microscope.

\section{Indirect immunodotting}

The specimens of the nuclear matrix and chromosome scaffold were transferred to NC (nitrocellulose) film. BSA was used as control. The NC film was incubated in PBST (PBS containing $0.05 \%$ Tween $20, \mathrm{v} / \mathrm{v})$ and $5 \%(\mathrm{w} / \mathrm{v})$ skimmed milk powder at room temperature for $1 \mathrm{~h}$, washed three times in PBST for $10 \mathrm{~min}$ each. The film was incubated with rabbit anti-tropomyosin antibody at a 1:500 dilution in PBST/milk containing $1 \%$ sheep serum at $37^{\circ} \mathrm{C}$ for $2 \mathrm{~h}$, washed three times in PBST, and then incubated with horseradish peroxidase conjugated sheep antirabbit IgG antibody at a $1: 500$ dilution in $\mathrm{PBST} / \mathrm{milk}$ containing $1 \%$ sheep serum at $37^{\circ} \mathrm{C}$ for $1 \mathrm{~h}$, washed three times in PBST. The antigen-antibody complex was visualized by incubation of the washed film with $0.5 \mathrm{mg} / \mathrm{ml} \mathrm{DAB}$ (diamino-benzidine) in PBS containing $0.006 \%(\mathrm{v} / \mathrm{v}) \mathrm{H}_{2} \mathrm{O}_{2}$ for 1 $2 \mathrm{~min}$.

\section{Indirect immunogold labeling}

The specimens were collected from the synchronized plasmodia in interphase and metaphase, fixed in a mixture of $1.5 \%$ gluteraldehyde and $4 \%$ paraformaldehyde for $2 \mathrm{~h}$, and then dehydrated in ethanol, embedded in Lowicryl K4M resin. Sections (60-80 nm thick) were cut with LKB-V ultratome, disposed in $1 \%$ saturated $\mathrm{NaIO}_{4}$ for $45 \mathrm{~min}$ and $0.1 \mathrm{M} \mathrm{HCl}$ for $10 \mathrm{~min}$, and then blocked with 1\% BSA in PBSTG (PBST containing $15 \mathrm{mM}$ glycine, $\mathrm{pH}$ 7.4) at room temperature for 15 min. After that, the specimens were incubated with rabbit anti-tropomyosin antibody at a 1:40 dilution in PBSTG at room temperature for $1 \mathrm{~h}$ and at $4{ }^{\circ} \mathrm{C}$ overnight, washed in PBSTG and incubated with protein A-colloidal gold at a 1:20 dilution in PBSTG at room temperature for $1 \mathrm{~h}$. The specimens were finally washed in distilled water, air dried, observed and photographed with an Hitachi-600 transmission electron microscope. Control grids were interacted only with protein A-colloidal gold.

\section{RESULTS}

\section{Protein analysis of nuclear matrix and chromosome scaffold}

Nuclear matrix and chromosome scaffold were prepared from the isolated nuclei (Fig 1A) and chromosomes (Fig 1B) according to the methods mentioned in materials and methods. The results of protein gel electrophoresis showed about 30 polypeptides in the nuclear matrix (Fig 2A) and about 20 polypeptides in the chromosome scaffold (Fig 2B). Most polypeptides of the nuclear matrix are identical with that of the chromosome scaffold in molecular weight, while, some polypeptides found in the nuclear matrix were absent or present in reduced quantity in the chromosome scaffold (compare Fig 2A and Fig $2 \mathrm{~B}$ ). A $37 \mathrm{kD}$ polypeptide which was equivalent to tropomyosin in molecular weight was found in both the nuclear matrix and chromosome scaffold (Fig 2, arrow indicated).

Detection of tropomyosin with immunofluorescence technique 
Tromyosin localized in Physarum polycephalum

The nuclear matrix and chromosome scaffold labeled with anti-tropomyosin antibody emanated bright fluorescence when observed on the fluorescence microscope (Fig 3A and B), and the fibrillar nature of the nuclear matrix could be recognized (Fig 3A). No bright fluorescence was found in the controls incubated only with FITC conjugated secondary anti-rabbit IgG antibody (Fig 3C), indicating that the experimental system was highly specific and that the bright fluorescence observed was derived from tropomyosin.

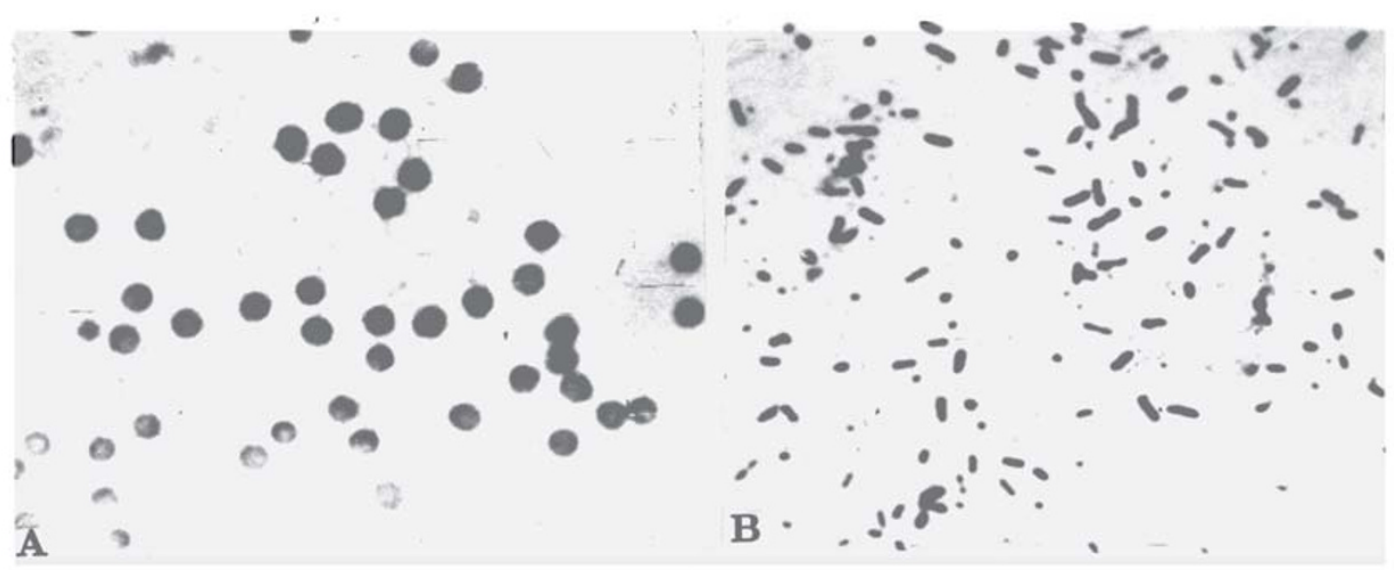

Fig 1. Isolated nuclei and chromosomes of Physarum polycephalum. Stained with Carbol fuchsin. A. nuclei $(\times 800)$, B. chromosomes $(\times 1800)$.
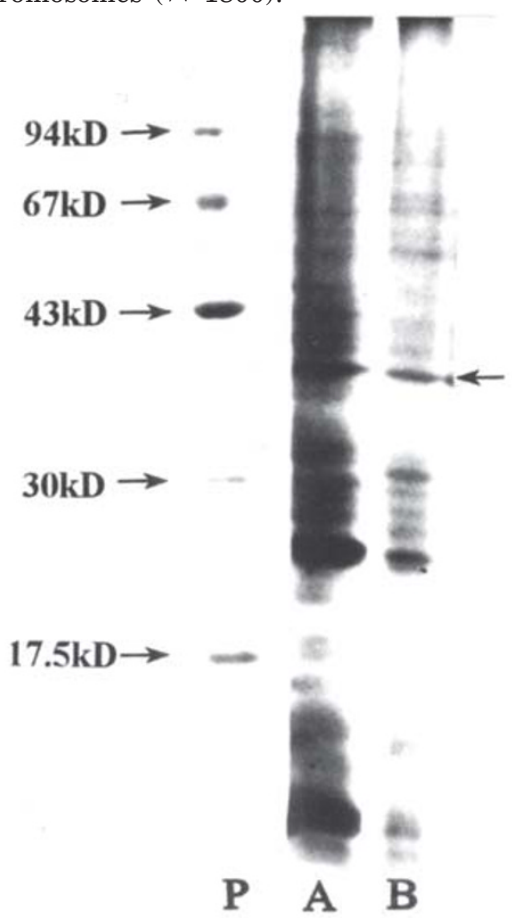


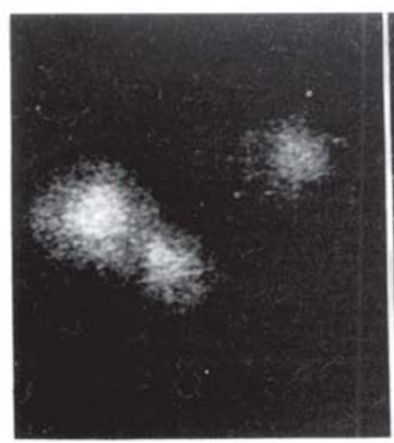

A

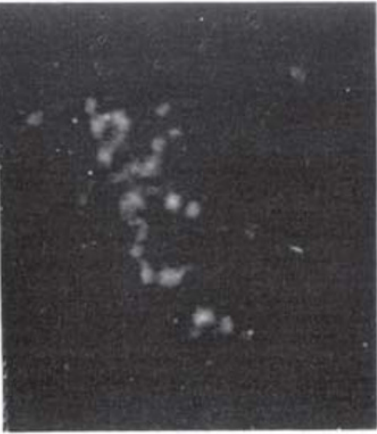

B

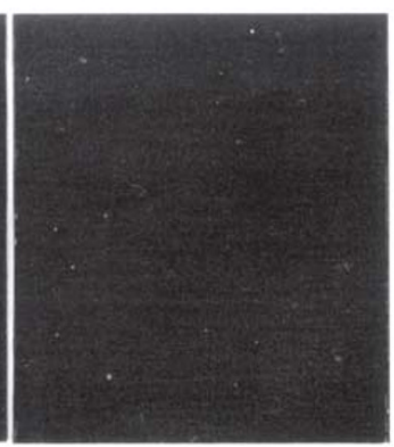

C

Fig 3. Photographs of indirect immunoffuorescence test.

A. Nuclear matrix labeled with rabbit anti-tropomyosin antibody $(\times 2200)$.

B. Chromosome scaffold labeled with rabbit anti-tropomyosin antibody $(\times 2500)$.

C. Controls. Labeling of rabbit anti-tropomyosin antibody was omitted.

\section{Detection of tropomyosin with immunodotting}

The protein preparations of the nuclear matrix and chromosome scaffold showed color reaction when incubated with rabbit anti-tropomyosin antibody and detected with horseradish peroxidase conjugated secondary antibody as described in "Materials and Methods". The color was gradually weakened along with the dilution of the protein preparations and finally became undetectable. No color reaction was observed in the controls which were incubated only with BSA. The results further verified that the antigen identified by anti-tropomyosin antibody existed in the nuclear matrix and chromosome scaffold.

\section{Localization of tropomyosin with immunoelectron microscopy}

Many gold particles representing tropomyosin were observed in the sections of both interphase nuclei and metaphase nuclei previously incubated with anti-tropo-myosin antibody. Gold particles were scattered in the interphase condensed chromatin, nucleoplasm and nucleolus (Fig 4A) and metaphase chromosomes (Fig 4C). In controls which were incubated only with protein A-colloidal gold, few gold particles were observed in interphase nucleus (Fig 4B) and metaphase chromosomes (Fig 4D). The statistical data (Tab 1) showed that the densities of gold particles in anti-tropomyosin antibody incubated interphase nuclei and metaphase chromosomes were $63.12 / \mu \mathrm{m}^{2}$ and $71.05 / \mu \mathrm{m}^{2}$, respectively, much higher than that of the interphase nuclei and metaphase chromosomes in control group which were only $3.08 / \mu \mathrm{m}^{2}$ and $4.91 / \mu \mathrm{m}^{2}$. These results indicate that the gold particles observed in the specimens were mainly due to the specific combination between the antibody and antigen and that tropomyosin was dispersively distributed in the nuclei and chromosomes. 


\section{Tromyosin localized in Physarum polycephalum}

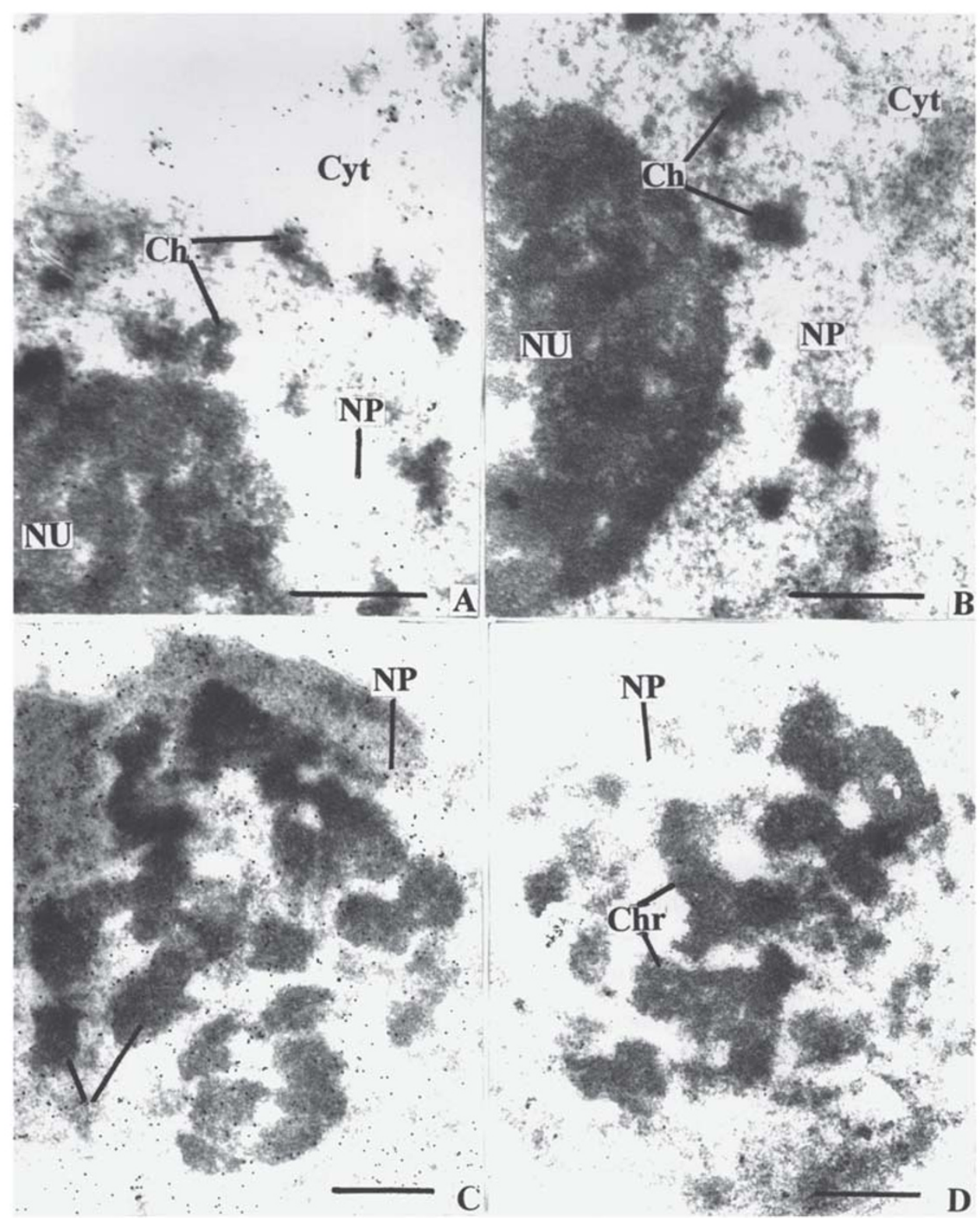

Fig 4. Photographs. of immunoelectron microscopy. A. A portion of an interphase nucleus incu bated with rabbit anti-tropomyosin antibody and detected with protein A-colloidal gold, showing many gold particles distributed in nucleolus (NU), nucleoplasm (NM), chromatin $(\mathrm{Ch})$ and cytoplasm $(\mathrm{Cyt})(\times 39000)$. B. A portion of an interphase nucleus in controls which were incubated only with protein A-colloidal gold, a few gold particles were found in the nucleus and cytoplasma $(\times 39000)$. C. A metaphase nucleus incubated with anti-tropomyosin antibody and detected with protein A-colloidal gold, showing that there were many gold particles in chromosomes $(\mathrm{Chr})(\times 30000)$. D. A metaphase nucleus in controls which were incubated only with protein A-colloidal gold, a few gold particles were present in the chromosomes $(\times 30000)$. Bar $=0.5 \mu \mathrm{m}$ 
Zeng XL et al.

Tab 1. Densities of gold particles in nuclei and chromosomes (particle number $/ \mu \mathrm{m}^{2}$ )

\begin{tabular}{lcccc}
\hline & $\begin{array}{c}\text { Nuclei } \\
\text { Experimental Group }\end{array}$ & Control & $\begin{array}{c}\text { Chromosomes } \\
\text { Experimental Group }\end{array}$ & Control \\
\hline 1 & 60.07 & 2.87 & 74.28 & 6.52 \\
2 & 58.91 & 3.05 & 69.41 & 3.93 \\
3 & 68.22 & 4.25 & 65.87 & 4.02 \\
4 & 66.33 & 2.54 & 73.62 & 5.11 \\
5 & 62.11 & 3.69 & 71.92 & 4.95 \\
M & 63.12 & 3.08 & 71.05 & 4.91 \\
SD & 4.01 & 0.69 & 3.44 & 1.09 \\
\hline
\end{tabular}

M: Mean; SD: Standard deviation.

\section{DISCUSSION}

Many authors have analysed the protein composition of the nuclear matrix and chromosome scaffold with the SDS-PAGE technique[1, 10, 19, 24-26], but their results did not give an unequivocal view about the composition as different materials and methods were used in their experiments. Since nuclear matrix and chromosome scaffold are complicated and dymanic complex of proteins, and, moreover, protein gel electrophoresis itself can not identify the individual proteins, so further understanding of the components of the nuclear matrix and chromosome scaffold is still necessary

In recent years, some authors have ascertained some proteins of the nuclear matrix and chromosome scaffold with immunocytochemical method. Earnshaw et al.[11] and Adachi et al.[12] indicated that Topoisomerase II is a component of the chromosome scaffold and nuclear matrix. Nakayasu and Berezney[13] identified, with two dimensional IEF/SDS-PAGE and immunobloting, laminins A, B, C, nucleolar protein B23 and some matrins as components of the nuclear matrix in a broad sense. Lang and Loidl[ith the results o16] reported that a $65 \mathrm{kD}$ and a $67 \mathrm{kD}$ lamin-like proteins were detected in the nuclear matrix. Grabber et al[14] and Eberharter et al[15] demonstrated that intermediate fibre protein was the component of the nuclear matrix. Some previous experiments indicated that a $37 \mathrm{kD}$ polypeptide which is equivalent to tropomyosin in molecular weight existed in the nucler matrix and chromosome scaffold[15, 17-20], and this polypeptide might represent tropomyosin[19]. Our experiments of protein analyses showed that a $37 \mathrm{kD}$ polypeptide was present in the nuclear matrix and chromosome scaffold of P. polycephalum, which is consistent wf previous reports. Furthermore, our results of immunodotting, immunofluorescence and immunoelectron microscopy simultaneously localized tropomyosin in the nuclear matrix and chromosome scaffold of $\mathrm{P}$. polycephalum. Based on all these results, we suggest that tropomyosin may be present in the nuclear matrices and chromosome scaffolds of various eukaryotes.

Tropomyosin is one of actin-binding proteins, which usually coexists with actin in a wide range of cytoplasmic structures and stabilizes actin filaments by binding along the 
Tromyosin localized in Physarum polycephalum

length of the filaments[27]. We previously reported that actin is the component of the nuclear matrix and chromosome scaffold[28-29], but it is unclear about the functions of actin and actin-binding proteins in the nuclear matrix and chromosome scaffold. Hao et al. found that the chromosome construction process comprises two steps, i.e. reorganization of chromatin and condensation of chromosomes, and the non-histone proteins of chromosome scaffold may be closely related to the process[30]. Taking these together, we suggest that tropomyosin may cofunction with actin in the process of chromosome construction.

\section{ACKNOWLEDGMENTS}

This study was supported by a grant from National Natural Science Foundation of China (No: 39130060). We are indebted to Dr. Philipe Albert, Cytology Laboratory of Reims University, France, for providing us with the strain TU291.

\section{REFERENCES}

[1] Berezney R, Coffey DS. 1974. Identification of a nuclear protein matrix. Biochem Biophys Res Commun 1974; 60:1400-17.

[2] Comings DE, Okada TA Nuclear protein III: the fibrillar nature of nuclear matrix. Exp Cell Res 1976; 103:341-60.

[3] Adolph KW, Cheng SM, Laemmli UK. Role of nonhistone proteins in metaphase chromosome structure. Cell 1977a; 12:805-16.

[4] Adolph KW, Cheng SM, Paulson JR, Laemmli UK, 1977b Isolation of a protein scaffold from mitotic Hela cell chromosomes. Proc Natl Acad Sci USA 1977b; 74:4937-41.

[5] Paulson JR. Scaffold morphology in histone-depleted Hela metaphase chromosomes. Chromo-soma 1989; 97:289-95.

[6] Zhao J, Hao S, Xing M. The fine structure of the mitotic chromosome core (scaffold) of Trilophidia annulata. Chromosoma 1991; 100:323-9.

[7] Bekers AGM, Guzen HJ, Taalman RDFM, Wanka F. Ultrastructure of the nuclear matrix from Physarum polycephalum during the mitotic cycle. J Ultrastruc. Res 1981; 75:350-62.

[8] Pienta KJ, Coffey DS. A structrural analysis of the role of the nuclear matrix and DNA loops in the organization of the nucleus and chromosome. J Cell Sci 1984; suppl. 1:125-35.

[9] Kaufmann SH, Shaper JH. Association of Topoisomerase II with the hepatoma cell nuclear matrix: the role of intermolecular disulfide bond formation. Exp Cell Res 1991; 192:511-23.

[10] Capco DG, Wan KM, Penman S. The nuclear matrix: three dimentional architecture and protein composition. Cell 1982; 29:847-58.

[11] Earnshaw WC, Halligan B, Cooke CA, Heck MMS, Liu LE. Topoisomerase II is a structural component of mitotic chromosome scaffolds. J Cell Biol 1985; 100:1706-15.

[12] Adachi Y, Kas E, Laemmli UK. Peferential coperative binding of DNA TopoII to scaffold-associated regions. 1989; The EMBO Journal 8:3997-4006.

[13] Nakayasu H, Berezney R. Nuclear matrins: Identification of the major nuclear matrix proteins. Proc Natl Acad Sci USA 1991; 88:10312-6.

[14] Grabher A, Eberharter A, Gstraunthaler G, Loidl P. Characterization of nuclear matrix proteins of Physarum polycephalum and mammalian. Cell Biol Intern Rep 1992; 16:1151-7.

[15] Eberharter A, Grabher A, Gstraunthaler G, Loidl P. Nuclear matrix of the lower eukaryote Physarum polycephalum and mammalian epithelial LLC-PK cell line (A comprehensive investigation of different preparation procedures). Eur J Biochem 1993; 212:573-80.

[16] Lang S, Loidl P. Identification of proteins immunologically related to vertebrate lamins in the 
Zeng XL et al.

nuclear matrix of the myxomycete Physarum polycephalum. European J Cell Biol 1993; 61:177-83

[17] Mitchelson KR, Bekers AGM, Wanka F. Isolation of a residual protein structure from nuclei of the myxomycete Physarum polycephalum. J Cell Sci 1979; 39:247-56.

[18] Lewis CD, Lebkowski JS, Daly AK, Laemmli UK. Interphase nuclear matrix and metaphase scaffolding structure. J Cell Sci 1984; (suppl.) 1:103-22.

[19] Pieck AGM, van de Velden HMW, Rijken AAM, Neis JM, Wank F. Protein composition of the chromosomal scaffold and interphase nuclear matrix. Chromosoma 1985; 91:137-44.

[20] Waitz W, Loidl P. In situ preparation of the nuclear matrix of Physarum polycephalum: ultrastructural and biochemical analysis of different matrix isolation procedures. J Cell Sci 1988; 90: 621-8.

[21] Daniel JW, Baldwin HH. Methods of culture of plasmodial myxomycetes. in: Prescott, D. M.(ed.): Methods in Cell Physiology, 1964; Vol 1. Academic Press. New York, pp. 9-41.

[22] Mohberg, J, Rusch HP. Isolation and DNA content of nuclei of Physarum polycephalum. Exp Cell Res 1971; 66:305-16.

[23] Laemmli UK. Cleavage of structural proteins during assembly of the head of Bacteriophage T4. Nature 1970; 227:680-5.

[24] Berezney R, Coffey DS. Nuclear matrix: isolation and characterization of framework structure from rat liver nuclei. J Cell Biol 1977; 73:616-37.

[25] Adolph, KW. Organization of chromosomes in Hela cell: Isolation of histone-depleted nuclei and nuclear scaffolds. J Cell Sci 1980; 42:291-304.

[26] Matsui S, Antoniades G, Basler J, Berezney R, Sandberg AA. Nuclear matrix versus chromosome scaffold: structural basis of eukaryotic chromatin. J Cell Biol 1981; 91: 60a.

[27] Alberts B, Bray D, Lewis J, Raff M, Roberts K, Watson JD. Molecular biology of the cell. 3rd ed. Garlard Publishing Incorperation Press, London 1994; pp. 613-44.

[28] Zeng X, Jiao MD, Wang XG, Hao S. Actin is a constituent of the nuclear matrix and chromosome scaffold in Physarum polycephalum. Acta Botanica Sinica. 1997; 39:691-6.

[29] Wan LH, Xing M. Actin is immunolocalized in the nuclei and chromosomes of Vicia faba. Acta Botanica Sinica 1977; 39:685-90.

[30] Hao S, Jiao M, Zhao J, Xing M, Huang B. Reorganization and condensation of chromatin in mitotic prophase nuclei of Allium cepa. Chromosoma 1994; 103:432-40. 